\title{
Linking behavioural ecology and oceanography: larval behaviour determines growth, mortality and dispersal
}

\author{
Øyvind Fiksen ${ }^{1, *}$, Christian Jørgensen ${ }^{1}$, Trond Kristiansen ${ }^{1,3}$, Frode Vikebø ${ }^{1,2, * *}$, Geir Huse ${ }^{2}$ \\ ${ }^{1}$ University of Bergen, Department of Biology, PO Box 7800, 5020 Bergen, Norway \\ ${ }^{2}$ Institute of Marine Research, PO Box 1870 Nordnes, 5817 Bergen, Norway \\ ${ }^{3}$ Present address: University of North Carolina, Department of Marine Sciences, Campus Box 3300, Chapel Hill, \\ North Carolina 27599-3300, USA
}

\begin{abstract}
Highly resolved general circulation models (GCMs) now generate realistic flow fields, and have revealed how sensitive larval drift routes are to vertical positioning in the water column. Sensible representation of behavioural processes then becomes essential to generate reliable patterns of environmental exposure (growth and survival), larval drift trajectories and dispersal. Existing individual-based models involving larval fish allow individuals to vary only in their attributes such as spatial coordinates, and not in their inherited behavioural strategies or phenotypes. We illustrate the interaction between short-term behaviour and longer-term dispersal consequences applying a model of larval cod Gadus morhua drifting in a GCM, and show how variations in swimming behaviour influence growth and dispersal. We recommend a deep integration of oceanography and behavioural ecology. First, we need to understand the causes and survival value of behaviours of larval fish, framed in terms of behavioural ecology. Second, we need practices to address how drift and dispersal of offspring are generating spawning strategies (timing and location) of adults, using life history theory. Third, the relative importance of local growth and mortality versus the need to drift to particular areas depend strongly on the mobility of organisms at the time of settling, or the spatial fitnesslandscape. The field of 'individual-based ecology' provides sound methods to approach this interface between evolutionary theory and physical oceanography.
\end{abstract}

KEY WORDS: Behavioural rules · Larval ecology · Individual-based models · General circulation models $\cdot$ Predation $\cdot$ Habitat selection

\section{INTRODUCTION}

The sea is a constantly moving habitat, structured by physical processes. For fish and other marine organisms, this constrains dispersal and habitat choice, but it also harbours opportunities. Organisms can exploit eddies and circular current systems for retention within an area (e.g. Sinclair 1988), or hitch-hike with tidal or vertically sheared currents flowing in desirable directions (Harden Jones et al. 1979). Mature adults of many species swim long distances to release their fertilised eggs, and let currents transport the developing early life stages to favourable nursery areas (Harden Jones 1968).
We do not intend here to review or synthesise the vast field of individual-based modelling in larval fish ecology. Nor are we reviewing the linkages between recruitment and dispersal in marine populations. Instead, we argue that the integration of larval behaviour with general circulation models is a key step forward to improve our understanding of larval survival, growth and dispersal. Behaviour is the central mechanism that links these 3 elements together, despite how restricted the behavioural repertoire of larvae may seem. There are primarily 2 lines of argument leading to this conclusion. First, compared to adult fish, the outcome of larval behaviour is more tightly connected to physical oceanography. Lar- 
vae distributed only a few metres apart in the vertical can end up in totally different geographical areas (Hinckley et al. 1996, Hare et al. 2005, Vikebø et al. 2005), which leaves a large scope for behaviour to influence dispersal as well as the environment for growth and mortality along the drift trajectory. Second, feeding opportunities and predation risks are spatially correlated for plankton. This is driven by the exponentially decreasing vertical profile of light-the key determinant for encounter rates with both predators and prey (Aksnes \& Giske 1993). Larvae can control their exposure to light through vertical positioning, and thus effectively influence their own survival and growth (e.g. Olla et al. 1996). Besides these 2 main arguments, larval ecology has farreaching implications for the life-history strategies of adults. The best spawning sites regarding larval drift patterns, growth and survival may require extensive spawning migrations at the adult stage, potentially conflicting with alternative ways to use energy and time.

An unfolding of larval fish ecology therefore requires an approach integrating physical oceanography and behavioural ecology, interpreted in the perspective of life-history theory. Using individual-based models (IBMs) rich in mechanistic detail, one can focus at the individual and let ecology emerge from individual processes; an approach recently termed 'individual-based ecology' (Grimm \& Railsback 2005). For larvae, this would include processes such as temperature-dependent growth and starvation, encounter rates with prey and predators that depend on e.g. light and turbulence, and various adaptive behavioural strategies such as habitat selection, activity pattern and schooling. When scaling up to populations, this perspective views ecology as emerging from individuals and their processes. New patterns that can be compared with data then arise at the population level (Grimm et al. 2005), for example temporal and spatial distributions, growth variation between years and areas, and what can be considered good spawning sites and times.

Present use of IBMs in oceanography is hampered by the lack of individual variability in behaviour (genotypes), and by the absence of fitness as the criterion to model natural selection processes among alternative behavioural strategies. It is often tempting to simply impose behaviour on individuals, or to implement caricatures of observed behaviours in models, making them more descriptive and less explanatory. The assumption of fixed individual behaviour in, for instance, habitat selection (they follow prescribed trajectories) has some drawbacks: (1) the modeller determines to a large extent how growth and mortality rates should be traded against each other; (2) the larvae cannot respond behaviourally to changes in the environment; (3) the potentially conflicting objectives of short-term optimisation of growth and mortality versus long-term drifting in particular directions cannot be studied; and (4) it is impossible to predict how environmental change may alter behaviour through natural selection unless individual variability and heritability are included. The aim of the present paper is to clarify some methodological concepts and promote the use of evolutionary IBMs in conjunction with general circulation models to address the ecology of early marine life stages.

Larval ecology has a strong tradition in dealing with mechanisms: from miniature biomechanics and behaviour, via influence from physical environmental variables and oceanography, to the capabilities and constraints of sensory systems. Mechanistically rich representations, including behaviour and life histories, are essential to capture interactions between environmental variability and recruitment success, or to understand the ability of fish in general to adapt to environmental change and human activities such as harvesting (Jørgensen et al. 2006). A largely unutilised potential is, however, that existing IBMs of larval fish and zooplankton do not include larval behavioural strategies as adaptive traits, nor do the models analyse evolutionary implications. This paper has 3 sections. First, we present the role of behaviour for marine larvae in a drift phase, and how this constrains adult lifehistory strategies. In the second part, we focus on concepts that can promote an evolutionary interpretation of active movements by drifting marine larvae. In the third part, we discuss candidate modelling frameworks and some recommendations for future research.

\section{IMPORTANCE OF BEHAVIOUR FOR GROWTH, MORTALITY AND DISPERSAL}

Larval behaviour does not imply cognition or rationally made decisions. Larvae simply execute genetically pre-programmed responses to internal states or external stimuli. Since there are always small variations in genetic predispositions between individuals and since behavioural traits are heritable (Plomin et al. 2000, Fitzpatrick et al. 2005), individuals encoded to perform behaviour that benefits their growth or survival will simply increase in numbers over the generations (Fisher 1930, Dawkins 1976). In this way, evolution leads to behavioural adaptations to the prevailing conditions. Consequently, the answer to the first question is yes: we would indeed expect that larvae have behaviour and that it is of a type that appears rational to a human observer.

We first identify 2 important effects of behaviour. Vertical positioning influences (1) immediate growth and mortality rates and (2) large-scale and long-term 
drift and dispersal. These 2 effects are not independent-priorities for one will influence the other.

\section{Mortality and growth emerge from larval behaviour}

The pelagic realm is characterised by strong environmental gradients in the vertical. Light may be the most influential physical variable structuring both productivity and predation in the pelagic (Aksnes et al. 2004). Because light decreases exponentially with depth, vertical behaviour can have tremendous effects on encounter rates with prey (spot prey in the light) and predators (hide in the dark). Habitat selection of larvae influences both growth and predation risk with a trade-off between the two: higher growth can normally be achieved only by accepting also a higher mortality. These rates must therefore be emergent properties of models, resulting from behavioural tradeoffs, rather than imposed or parameterised values determined by the modeller (Grimm \& Railsback 2005).

While growth is often modelled in great detail (Lough et al. 2005), mortality is rarely modelled explicitly. Cohort survival is sensitive to small variations in mortality rates, and we need to include both the basic mechanisms and the environmental forcing of predation processes in models of larval fish. This is a pre-requisite to understanding the trade-offs between growth and survival and to appreciate the role of behaviour in determining these rates.

Increased body size decreases predation risk from small and abundant predators (Bailey \& Houde 1989). Growth is therefore important to fish larvae since it reduces the time spent in the most vulnerable phase (Houde 1997). In evolutionary terms, this would act as a motivation to maintain high growth rates even if this involves more exposure to predators. At the same time, increasing body size makes larvae more visible, thereby increasing their vulnerability to visual predation in the euphotic zone (Aksnes \& Giske 1993). That fish larvae show ontogenetic development in depth distribution (Leis et al. 2006) and diel vertical migration (Lough \& Potter 1993) is likely a response to changing mortality patterns as body size increases.

When foraging is traded against risk of predation, more prey may not lead to higher growth rates, but instead to lower predation rates (McNamara \& Houston 1987, Lima \& Dill 1990). Such behavioural mechanisms could confound studies on the link between prey availability and larval growth rates, with implications for observation programmes trying to establish the relationship between growth and prey abundance in larval fish. As an example, larval cod Gadus morhua tend to grow at temperature-limited rates over a range of environmental conditions in field observations (Folk- vord 2005). Apparently, this contradicts the study of Beaugrand et al. (2003), which suggested a connection between zooplankton availability and recruitment success of North Sea cod. However, if feeding or growth is traded against predation risk, food abundance may not influence growth directly, but instead modify the strength of a recruiting cohort through behaviourally mediated exposure to predation (Fiksen et al. 2005). At low food availability, larval cod can maintain high growth rates either by increasing their activity level at the cost of running into ambush invertebrate predators more frequently, or by spending more time at higher light intensities where they are more likely to be detected by visually searching raptorial fish. Thus, although there is no observation of food-limited growth, low prey abundance may act through behavioural compensations and influence mortality and thereby recruitment variability.

However, a recurrent observation in larval fish ecology is that faster-growing larvae tend to survive better (e.g. Takasuka et al. 2003, Nielsen \& Munk 2004). In a constant environment this would contradict the classical growth-mortality trade-off, but in a variable environment and with state-dependent behaviour, this is exactly what we would expect. Then, individuals accidentally in a low food environment would have reduced internal states (stomach fullness, condition) and higher motivation for growth. They would act more boldly, be less fearful (less diel vertical migration or schooling and higher activity) and be more exposed to predation. The strength of such behavioural effects relative to starvation or reduced escape abilities is, however, difficult to disentangle.

\section{Larval drift and dispersal}

Minor vertical displacements may expose larvae to different flow schemes due to vertical shear. For example, particles dropped at the Northeast Arctic cod spawning grounds at 10 and $20 \mathrm{~m}$ depth and traced for $100 \mathrm{~d}$ end up 100s of kilometres apart (Vikebø et al. 2005). Using a general circulation model (GCM) over the Gulf of Maine, Huret et al. (2007, this Theme Section) showed how even small differences in initial vertical position of cod eggs and larvae influenced the chance of drifting to suitable settlement, at least in stratified situations. This demonstrates the potential of habitat selection in the vertical in affecting large-scale dispersal. In addition, horizontal swimming does not necessarily have to compensate for displacement by currents: current strengths and directions vary in space and time, and even limited horizontal movements can associate the larvae more closely with certain current regimes. Leis et al. (2006) showed that larvae of several coral reef fish observed in the field were 


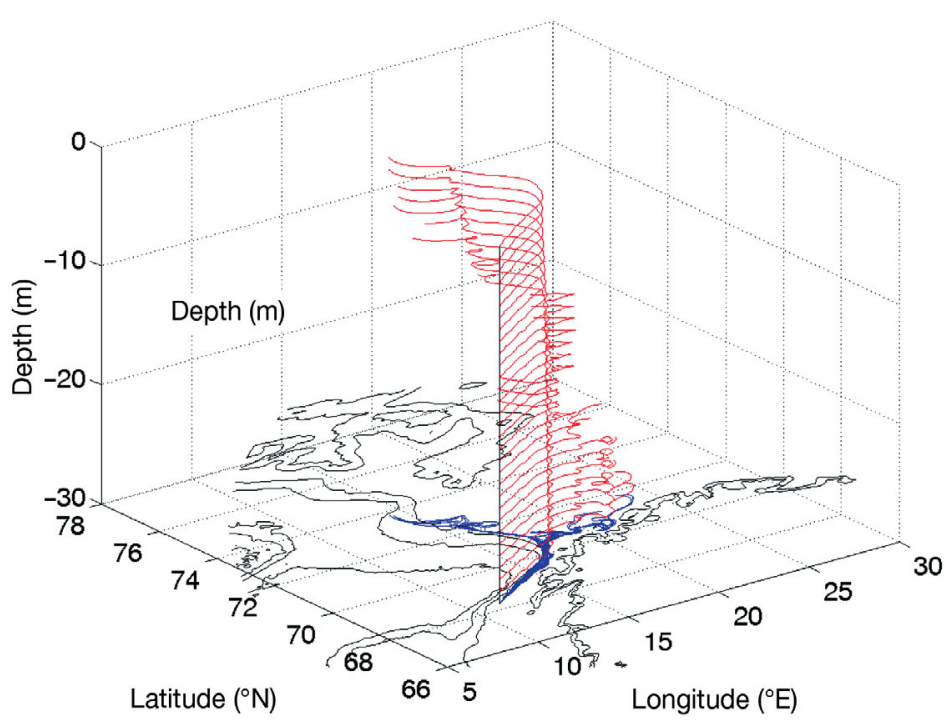

Fig. 1. Drift trajectories of larvae at fixed depths $(0$ to $30 \mathrm{~m})$ on 1 April and 1 mo forward in time. The larvae were released simultaneously from a fixed point at Moskenesgrunnen. Red lines show the drift trajectories in 3-dimensional space, while blue lines are the geographical projections of the trajectories. These can be grouped in 2 bundles, the deep ones drifting along the coast, and the shallow trajectories drifting offshore, northwards. See Vikebø et al. (2005) for details swimming in directions significantly different from random. It is not known what cues these larvae were using for orientation, but fish larvae have also been shown to detect reef sounds and the smell of conspecifics already at presettling stages (Wright et al. 2005).

An example of effects from vertical and horizontal swimming is illustrated in Fig. 1, which shows the trajectories of larvae drifting for 1 mo at fixed depths (1 to $30 \mathrm{~m}$ ) when released from Moskenesgrunnen, a typical spawning site for Atlantic cod in northern Norway. The physical model and the larval growth as a function of temperature are described in Vikebø et al. (2005). The simulations show a surprising potential for larvae to affect their likelihood of ending up in the Coastal Current or the Atlantic Current by swimming horizontally or vertically. Vertical positioning has a strong effect (Fig. 1), but even directional horizontal swimming at the reasonable velocity of 1 body length (BL) $\mathrm{s}^{-1}$ will significantly impact the trajectory of the larvae, at all depths (Fig. 2a). If the swimming speed were 3 BL $\mathrm{s}^{-1}$, then horizontal movements would

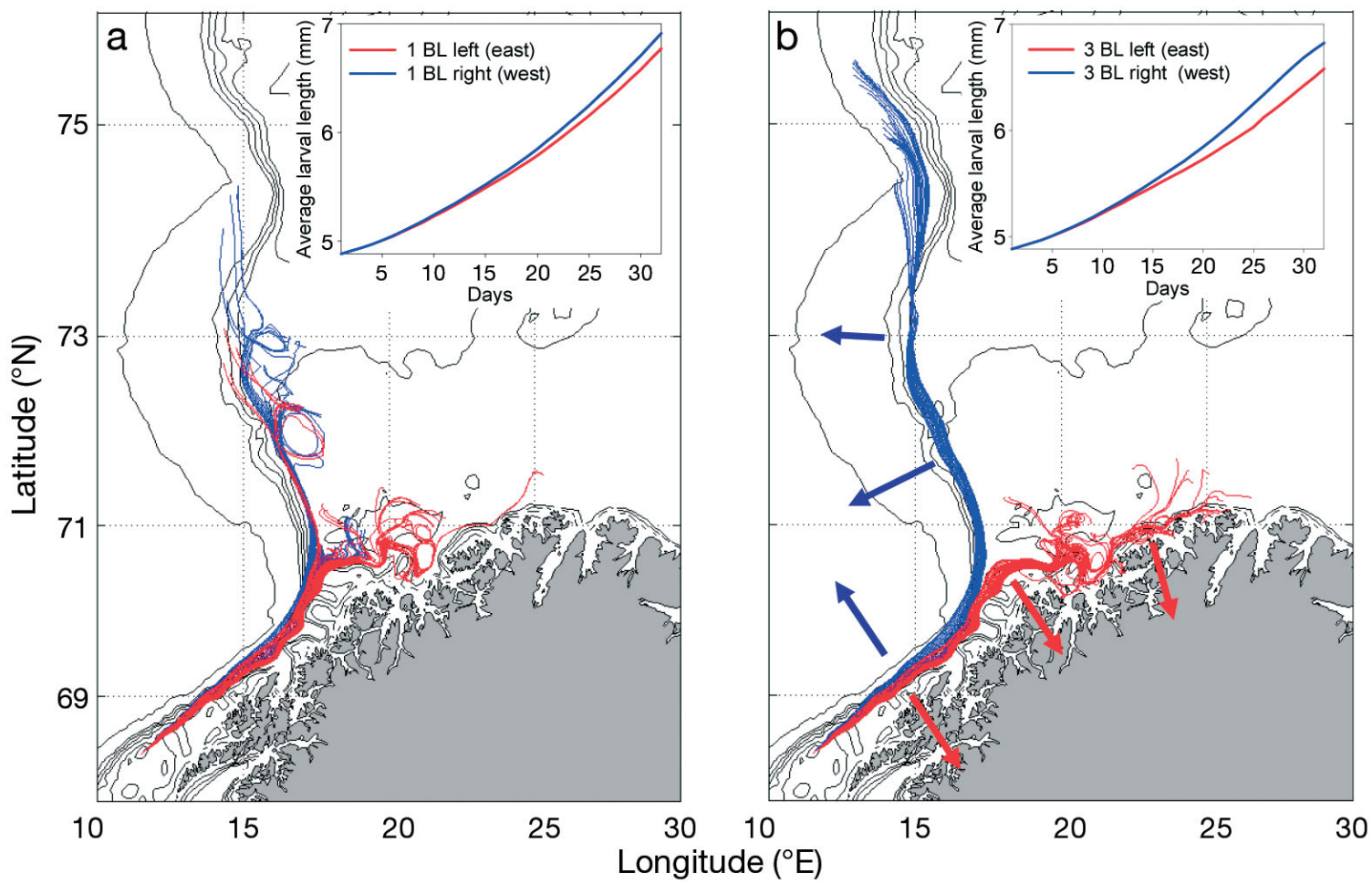

Fig. 2. Drift trajectories of larvae released at Moskenesgrunnen, northern Norway, on 1 April and 1 mo forward in time. Each line represents 1 larva inhabiting a fixed depth between 1 and $30 \mathrm{~m}$ (1 larva at each depth). Blue lines are larvae swimming constantly $90^{\circ}$ to the right of their upstream orientation (blue arrows), while red lines are larvae swimming constantly $90^{\circ}$ to the left (red arrows). They swim with a velocity of either (a) 1 or (b) 3 body lengths (BL) per second. Insets: average growth histories of the individuals. See Vikebø et al. (2005) for details 
override the effects of depth position completely in this particular region (Fig. 2b). Growth histories averaged over depths diverge for the 2 behaviours: swimming to the right, facing the currents (north-west direction), results in the largest size (insets in Fig. 2). However, this also leads larvae northwards, out of the Barents Sea.

Routine swimming speeds are in the range from 0.3 to $0.5 \mathrm{BL} \mathrm{s}^{-1}$ for a cod larvae (Skiftesvik 1992, Peck et al. 2006). Although this is much lower than the $3 \mathrm{BL} \mathrm{s}^{-1}$ used in the numerical example above, both field and laboratory observations suggest that other species have higher capabilities (Leis 2007, this Theme Section). In a study of 89 species of coral reef fish larvae in their later stages, $90 \%$ of the species could swim faster than the local currents at $13.5 \mathrm{~cm} \mathrm{~s}^{-1}$ (Fisher et al. 2005). The most common critical swimming speeds were 2 to 3 times as fast, meaning that swimming could significantly affect dispersal and settlement. Coral reef fish larvae have been measured to have critical swimming speeds of 4 to $29 \mathrm{BL} \mathrm{s}^{-1}$ (Fisher et al. 2005), and some species can swim $>20 \mathrm{~km}$ at a body length of $10 \mathrm{~mm}$ (Clark et al. 2005). Critical swimming speeds decrease with temperature, because viscosity is higher in colder water (Fuiman \& Batty 1997), which could lead to warm-water species having higher larval swimming capabilities than species inhabiting colder waters (Leis 2007). Observations of swimming speeds in the laboratory and in the field correspond well (Leis et al. 2006), and critical swimming speeds normally develop in early ontogeny, while endurance develops somewhat later (Clark et al. 2005).

Direct evidence for the influence of larval behaviour comes from an impressively well-sampled study on the damselfish, a coral reef fish that stays within the proximity of a home coral all its life. Surface currents transported the pelagic larvae away from the reef, but at some stage they sought depths $(60 \mathrm{~m})$ at which directional currents would bring them back to their native reef (Paris \& Cowen 2004). Studies such as this one exemplify how organisms can exploit ocean currents as a mechanism to influence dispersal. Other coral reef fish larvae also show ontogenetic shifts in depth, with some moving to shallower and some to deeper water as they grow larger (Leis et al. 2006). It would be interesting to know whether these depth shifts are due to changes in mortality rates or due to vertical shear and implications for drift trajectories or both.

\section{Parental trade-offs in spawning strategies}

The spatial and seasonal variability in growth and predation risk of fish eggs and larvae are important factors affecting the spawning strategies of adults.
Spawning will, however, not necessarily take place at the optimal spawning locations. Rather, the benefits eggs and larvae will have at any particular spawning location is part of a trade-off in the parental life-history strategy: How much time and energy should they invest in the spawning migration to obtain benefits for their offspring? For example, how should fish store energy over the year to produce offspring at particular times and places (Schwalme \& Chouinard 1999, Varpe et al. 2005), or how much energy, predation risk and lost feeding opportunities should they invest in the spawning migration (e.g. Slotte \& Fiksen 2000). The ecology of early life stages therefore provides keys to understanding fish life histories on the whole, as the spawning strategy indicates both how important location and timing are to larvae and how much adults invest in offspring quality.

\section{INTERPRETING FITNESS: THE EVOLUTIONARY ANALYSIS}

The pioneering work by Mullon et al. (2002) demonstrated how evolutionary reasoning could be combined with GCMs to understand why fish spawn in particular regions. They tested the implications of various assumptions about larval survival on the adaptive spawning location of anchovies Engraulis capensis in southern Benguela and related their results to environmental exposure (temperature) and geographical position (the risk of drifting offshore). Larvae that survived their drift phase spawned again at their natal spawning location and at the time they were spawned themselves. By repeating this procedure for some generations, successful parental spawning strategies emerged from assumptions made in the model.

In this section, we discuss methodological extensions that may extend this approach, which was focused towards the strategy of the adults. Having established that the inconspicuous behaviour of marine larvae can affect growth, mortality and dispersal dramatically, the obvious question is: How can we study its fitness consequences? In this section, we suggest a composite fitness measure that incorporates survival until settlement, the value of settlement in a given area and the value of body size at settlement. In addition, we recommend using IBMs with rule-based behaviour. A further discussion of alternative methodologies for implementation of these concepts is postponed until the section 'Modelling toolbox and recommendations'.

\section{Behavioural rules}

A behavioural strategy can be interpreted as a set of rules determining how organisms respond to their 
internal and external environment (e.g. directly as fixed strategies, as part of plastic strategies, behavioural rules, or as stimulus-driven neural networks), and how they are constrained by sensory input and physiological restrictions (Giske et al. 2003, Grimm \& Railsback 2005, Hutchinson \& Gigerenzer 2005). For drifting larvae, a key behavioural trait is vertical positioning, since growth, predation risk and horizontal advection are all functions of depth (Fig. 2).

The 'fixed-depth' rule applied in our example (Fig. 1) is obviously too simplistic. Larval fish change depth preference with ontogeny and size, with internal condition, such as hunger (stomach fullness), and also with the daily light cycle (Lough \& Potter 1993, Leis et al. 2006). This choice does not need to be conscious, but may be a genetically hard-wired response to sensory cues (instinctive behaviour).

Assuming that individuals have sensory information about growth $g_{z}$ and predation rate $m_{z}$ in a range of depths $z$, they may use this information to decide which depth to choose. We have developed a more detailed version of the rule-based larval behaviour described in Vikebø et al. (2007, this Theme Section). One option is a rule that maximises the instantaneous rate of mass increase (i.e. maximise $g_{z}-m_{z i}$ Persson \& De Roos 2003). This rule avoids the problems associated with the classical rule by Gilliam (minimise the ratio $m_{z} / g_{z}$ ) when growth rates approach zero or become negative, as discussed in detail by Railsback et al. (1999). However, it may be profitable to take higher or lower risk than specified by this rule; therefore, risk sensitivity should emerge in models rather than be defined in advance. We can formulate a rule where the selected depth $z_{i}$, specific to individual $i$, optimises the trade-off, modulated by risk sensitivity $\pi_{i}$, between habitat-specific growth and mortality rates:

$$
z_{i}=\operatorname{mazx}\left[\left(1-\pi_{i}\right) g_{z}-\pi_{i} m_{z}\right]
$$

A risk-averse (fearful) individual would carry $\pi_{i}$ values close to 1 , whereas a bold growth maximiser would have $\pi_{i}$ near 0 . The strategy $0 \leq \pi_{i} \leq 1$ thus has a straightforward interpretation as the risk sensitivity of an individual, while the risk sensitivity itself may be a mathematical function affected by a number of parameters translating local information into a value of $\pi_{i}$. The simplest version of the rule is $\pi_{i}=\beta_{i}$, then risk sensitivity is constant and influenced directly by a single gene. Such rules have been explored in more detail by Vikebø et al. (2007). The trade-off between growth and mortality may, however, be modulated by a number of stimuli, and the rule can easily be developed further by making $\pi_{i}$ a function of internal states, such as stomach fullness or body size.

Rules act as simple heuristics translating local information into different behaviours when environ- mental conditions change (Hutchinson \& Gigerenzer 2005). The ideal behavioural schedule should be evolutionarily robust, meaning it should work well across environmental variability, and be difficult to invade by alternative strategies in a long-term perspective. The rules should also conform to observed patterns of, e.g., distributions in depth or space from field studies (Grimm et al. 2005). The ultimate test is to set up gradients in the laboratory to experimentally challenge rules found by models and to see if larvae respond as predicted. Such experiments have generated much insight in limnology (e.g. Loose \& Dawidowicz 1994).

\section{Geographical fitness landscapes}

Some organisms, for instance barnacles, are sedentary after the larval drift phase and for the rest of their life. Then larval behaviour must be fine-tuned to utilise currents in finding settlement habitat. A first requirement is that the settling area provides suitable habitat for further growth and survival (Larsson \& Jonsson 2006). The settlement area has strong bearing on future reproductive success depending on circulationdriven connectivity.

Cowen et al. (2006) tracked dispersing larvae in a basin-wide study of the Caribbean using an ocean circulation model. Some reefs were highly connected, and larvae spawned there dispersed to multiple and sometimes distant reefs. Other spawning locations were reproductive dead-ends because ocean currents did not bring larvae close to any suitable settlement habitat. For species with limited mobility in their juvenile or adult stages, such a geographical picture of dispersal and settlement can be viewed as a fitness landscape: all that matters is to end up at a location where your offspring can survive and disperse to other suitable habitats. More-mobile species should be less concerned with their spatial location, and more focused on growth and mortality in their local environment along the drift trajectory. If juveniles and adults were mobile enough to compensate for a poor location, the fitness landscape would show smoother geographical variation.

What Mullon et al. (2002) did was actually to use a genetic algorithm to map the geographical fitness landscape based on a few assumptions about the early life stages in anchovies. This coupling of general circulation models and habitat connectivity with evolutionary reasoning make trade-offs in larval life and in adult spawning strategies explicit. Geographical position is not everything, however, and to strengthen the link with life-history evolution we need a broader perspective on what constitutes fitness. 


\section{Evaluating behavioural strategies}

What criteria should be used to assess fitness of different rules or strategies? If the full life cycle including reproduction is modelled, one can use emergent fitness rather than an explicitly formulated fitness criterion (Menczer \& Belew 1996, Giske et al. 1998, Strand et al. 2002). However, for models focusing on the larval phase it is often convenient to assess the success of individuals at a particular time or age, for example at settlement. There are different components that contribute to fitness, and below we have tried to split fitness consequences into functional categories. Let $V_{i}$ denote fitness evaluated at the end of the drift phase when an individual $i$ following strategy $S_{i}$ (a rule or a set of rules) has reached a given size or developmental stage, then:

$$
V_{i}\left(S_{i}\right)=l_{i} f\left(W_{i}\right) G\left(x_{i}, y_{i}\right)
$$

The first component here is the survival until settlement $l_{i}$. The second component is a function $f\left(W_{i}\right)$ that describes the fitness value of size $w_{i}$ at settlement. A larger body size may lead to increased competitive ability for food or shelter, or may influence starvation or predation rates after settlement. The last component includes the fitness consequences $G\left(x_{i}, Y_{i}\right)$ of settling at the geographical position $\left(x_{i}, Y_{i}\right)$. This can be found by making assumptions about habitat suitability, and should ideally include connectivity and the potential for future reproduction found through an iterative schedule such as in Mullon et al. (2002). In such cases, the value of a given settlement area should include also a time dimension, i.e. $G\left(x_{i}, y_{i}, t_{i}\right)$.

The second and third components are in essence all assumptions of expected future reproductive value given individual state and position at the end of the drift phase. It resembles the terminal fitness function known from dynamic programming methods in behavioural ecology (e.g. Houston \& McNamara 1999), which is typically a reward function of being in a particular state at a given time. The first component of fitness is accrued survival probability $l_{i}$ of a larva throughout the drift phase. Survival depends on the environment along the drift trajectory (predation and starvation) and individual risk sensitivity or behaviour. Fitness $V_{i}$ is then in units of expected lifetime reproductive success for a single individual following strategy $S_{i}$.

Eq. (2) is the simplest version of a fitness function. It summarises fitness elements from the water column, the drift trajectory and the settlement area (Fig. 3), i.e. tactic and strategic fitness components. One could envisage interaction effects between size and space for example, where a large body size gives advantages in some geographical areas compared to others. In that case the effect of size has to be accounted for together with the geographical fitness consequences, and the equation would become $V_{i}\left(S_{i}\right)=l_{i} G\left(w_{i}, X_{i}, Y_{i}\right)$. For example, size-dependent swimming abilities may reduce the importance of position at settlement for larger larvae. In our larval drift example, fitness may be assessed as proportional to larval length after $1 \mathrm{mo}$ (Fig. 2). However, the fitness of high temperature in
Fig. 3. This figure illustrates the local and strategic trade-offs in larval habitat selection. To the left are the classical behavioural elements of the pelagic environment, setting up a local trade-off between growth and survival. In the middle the large-scale drift consequences of local depth selection. The picture to the right illustrates the terminal settlement area when the drift phase is over. This area may also influence fitness and should be included in the evaluation of the success of the behavioural strategy. The table refers to the symbols introduced in the text

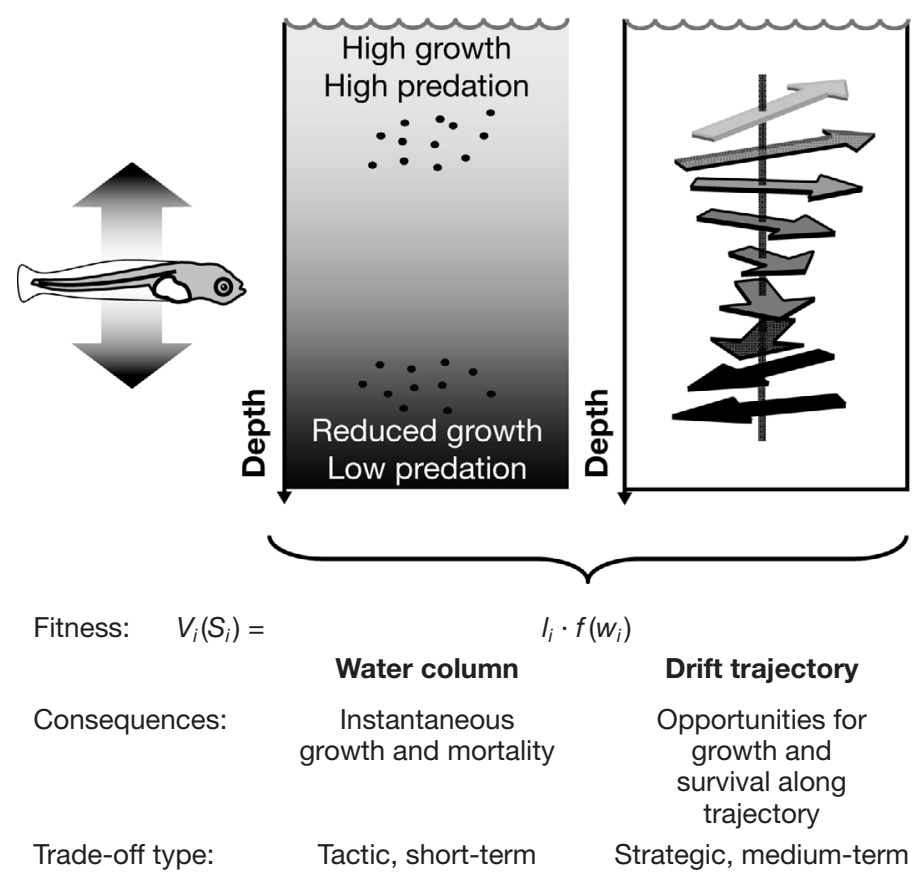

Trade-off type: Tactic, short-term Strategic, medium-term Strategic, long-term 
the 'Atlantic' drift trajectory must be weighted against the potential disadvantage of ending up in unfavourable areas, in our case in the deep off-shelf areas to the west or north of Spitsbergen. Larvae following short-term hedonic cues, such as high temperature, may end up as losers in the long term. A more realistic fitness measure would include the function $G\left(w_{i}, X_{i}, y_{i}\right)$, potentially derived from field data (Ciannelli et al. 2007), but this function is not easy to determine.

\section{MODELLING TOOLBOX AND RECOMMENDATIONS}

A blend of 4 different types of models is thus recommended to analyse the fitness consequences of larval behaviour: (1) models of the environment relevant to growth and survival; (2) mechanistic representations of how ecological processes are forced by the environment (growth, predation risk, drift patterns); (3) behavioural rules to derive adaptive responses or 'adaptive traits' in the terminology of Chambers (1993) and Grimm \& Railsback (2005); and (4) models evaluating the success of rules in terms of fitness or components of fitness (as in Eq. 2). While models of marine larvae traditionally have focused on the first 2 categories, we argue that the third and fourth elements are crucial to understanding the coupling between the environment and the success of organisms. Understanding both how and why marine organisms have adapted so intricately to their moving environment is a necessary prerequisite if we are to predict how fish populations will respond to changes in their environment and to harvesting. In the following, we will discuss requirements for such an integrated modelling effort.

\section{Physical and ecological environment}

General circulation models can generate 'offline' matrices of flow and environmental variables. As oceanographers develop libraries of such matrixes, including the representations of tidal variability, IBMs can track a large number of individuals or particles through high-resolution, 3-dimensional space. With current technology such offline particle models can be executed on desktop computers on time scales of hours.

A major challenge is how to capture spatio-temporal variability in prey and predator fields. One method is to assimilate available data on prey (e.g. Hinrichsen et al. 2005) or predators (Garrison et al. 2000) into models of larval fish, but such fields are scarce and may need to be supplemented by modelling.

\section{Individual properties}

When implementing an IBM, it is instructive to keep a distinct separation between the strategy that contains the rules that specify behaviour and the bookkeeping of the phenotype. It has been common to describe the phenotype of an individual using an attribute vector $A_{i, t}$ (Chambers 1993), which contains all the states $\left(\alpha 1_{i} \ldots, \alpha j_{i}\right)$ used to characterise the individual $i$ at time $t$, such as age, weight, stomach fullness, length and spatial co-ordinates $\left(x_{i}, y_{i}, z_{i}\right)$ :

$$
A_{i, t}=\left(\alpha 1_{i}, \alpha 2_{i}, \alpha 3_{i}, \ldots, \alpha j_{i}, x_{i}, y_{i}, z_{i}\right)
$$

High mortality quickly reduces population size and deteriorates variation between individuals, which leaves the composition of the model population vulnerable to chance events (analogous to genetic drift in small populations). This can be solved using super-individuals (Scheffer et al. 1995). A super-individual represents many identical individuals, and the number of identical siblings $\left(n_{s}\right)$ becomes an additional attribute:

$$
A_{s, t}=\left(\alpha 1_{s^{\prime}} \alpha 2_{s^{\prime}} \alpha 3_{s^{\prime}} \ldots, \alpha j_{s^{\prime}}, X_{s^{\prime}} y_{s^{\prime}} z_{s^{\prime}} n_{s}\right)
$$

Here, shown for super-individual $s$, the number of identical siblings $n_{s}$ is reduced in proportion to the mortality rate (Scheffer et al. 1995). The number of different super-individuals in the model population and, therefore, the variation between them remain the same. An alternative interpretation is that $n_{s}$ may represent the cumulative survival probability of individuals following strategy $s$. Super-individuals also link IBMs to population models and allow the simulation of 'true' abundances of fish populations (Huse et al. 2004).

The phenotype results from the individual's strategy in interaction with the environment. In IBMs this can be formalised by introducing a strategy vector $S_{i}$ (Huse 2001):

$$
S_{i}=\left(\beta 1_{i}, \beta 2_{i}, \beta 3_{i}, \ldots, \beta j_{i}\right)
$$

where $\beta j_{i}$ is the adaptive trait $j$ of individual $i$. The traits specified by the strategy vector can for example be life-history traits or behavioural strategies that specify how individuals should live their lives or use information from their local environment. In the context of larval ecology, typical traits could be the level of risk acceptance, the onset or degree of vertical migration, or built-in responses to light or temperature to mention a few. For the simplistic example presented in Figs. 1 $\& 2$, the strategy vector would be the depth-selected, swimming direction and swimming velocity. A strategy vector also makes it possible to include a multitude of stimuli in the decision rule, where sensory inputs are weighted differently (analogous to motivations) within individuals (Giske et al. 2003). Locally available information can also be processed by a neural network, 
where the strategy vector prescribes weights for each of the connections (Huse et al. 1999, Strand et al. 2002).

The combination of attribute and strategy vectors enables most relevant characteristics of individuals to be implemented in IBMs, and the approach also specifies how fixed parameters for a strategy translate into behavioural and phenotypical differences between individuals. The classification based on attribute and strategy vectors can be used to describe IBMs even though the actual programming implementation is not vector based, as, for example, in object-oriented programming (Maley \& Caswell 1993).

\section{Evolutionary algorithms}

The strategy vector may be considered as a genotype analogous to a biological chromosome, and we are therefore interested in how evolution would shape it over time. We can also interpret the strategy vector as a phenotype, and use the same type of algorithm to find optimal or adaptive types of behaviour. There are several alternative algorithms that search for solutions that evolution would favour. The broadest distinction is between optimisation models (e.g. Houston \& McNamara 1999, Clark \& Mangel 2000), which find the optimal solution to a given problem, and 'search heuristics' that use different types of search algorithms to find good and robust solutions, but not necessarily the optimal one (e.g. Holland 1992).

Because of the complexity of models that combine physical oceanography, drift patterns and behaviour, exhaustive search and optimality models rarely provide a viable route. Optimisation tools for finding the best possible behaviour are not available for the problem sketched in the previous sections. The reason is that a change in behaviour at any point in time will influence the future drift trajectory, and therefore one has no method for predicting the fitness consequences for the alternative behavioural options. Instead, one has to use heuristics, such as genetic algorithms, that simulate fast-forward evolution, or simply shower the models with solutions more like exhaustive search. These heuristic methods can be powerful search algorithms when one simulates populations that behave according to mathematically simple rules, and where individual variation in the rule parameters exists.

One suitable and widely used option is represented by genetic algorithms (Holland 1992, Huse et al. 1999). A genetic algorithm simulates evolution of the strategy vector by modelling a population consisting of individuals with different strategy vectors. Each generation, the individuals with highest fitness pass their strategy vector on to the next generation. The trait value is tested and improved iteratively over generations, and new variation can be introduced by processes analogous to mutation and recombination. This methodology searches for evolutionarily robust strategy vectors, for instance behavioural strategies that prevent larvae from drifting into harsh settlement regions.

\section{SUMMARY}

Selection of vertical habitat for larvae drifting in currents influences both the local short-term trade-off between growth and mortality and the more strategic and long-term consequences related to the large-scale circulation regime. The importance of ending up in particular habitats depends on the mobility of juveniles at settling. If organisms have strong swimming abilities at settlement, we expect them to prioritise growth and survival along the drift trajectory above settlement location. The procedure we have suggested here frames larval-behaviour and fish-spawning strategies in the tradition of evolutionary ecology, both conceptually and formally. We recommend IBM practices (Grimm \& Railsback 2005) that emphasise (1) numerous emergent properties from basic, transparent and mechanistic assumptions on growth, mortality, behavioural abilities and drift processes; (2) behavioural strategies or rules that show variability between individuals; and (3) selection processes that incorporate fitness consequences along the trajectory and at the settlement location. One efficient tool for such investigations is represented by models that simulate evolution based on genetic algorithms. Such models tackle sufficient complexity and are capable of evaluating consequences of larval behaviour in flow fields and integrating effects across several time scales. Modelling should be done in close collaboration with laboratory and field studies on larval behaviour, their abilities, constraints, and temporal and spatial distributions. We recommend modelling practices that use transparent and mechanistic processes in growth, mortality, behavioural abilities and drift; apply behavioural strategies or rules that allow true variability between individuals; and include an evolutionary selection procedure to assess fitness consequences along drift trajectories and at the settlement location. This procedure enables studies on how organisms can adapt to environmental change through natural selection.

Acknowledgements. We are most grateful to D. L. Aksnes and $\mathrm{J}$. Giske for their original views on mechanics and evolution in the sea, an important source of inspiration for this work. We acknowledge the Research Council of Norway for support, and reviewers for constructive suggestions. Thanks to Elizabeth North, Alejandro Gallego and Pierre Petitgas for organising the WKAMF Workshop, and to T. Torgersen and S. Eliassen for discussions and comments. 


\section{LITERATURE CITED}

Aksnes DL, Giske J (1993) A theoretical model of aquatic visual feeding. Ecol Model 67:233-250

Aksnes DL, Nejstgaard J, Sædberg E, Sørnes T (2004) Optical control of fish and zooplankton populations. Limnol Oceanogr 49:233-238

Bailey KM, Houde ED (1989) Predation on eggs and larvae of marine fishes and the recruitment problem. Adv Mar Biol 25:1-83

Beaugrand G, Brander KM, Lindley JA, Souissi S, Reid PC (2003) Plankton effect on cod recruitment in the North Sea. Nature 426:661-664

Chambers RC (1993) Phenotypic variability in fish populations and its representation in individual-based models. Trans Am Fish Soc 122:404-414

Ciannelli L, Dingsør GE, Bogstad B, Ottersen G, Chan KS, Gjøsæter H, Stiansen JE, Stenseth NC (2007) Spatial anatomy of species survival: effects of predation and climate-driven environmental variability. Ecology 88:635-645

Clark CW, Mangel M (2000) Dynamic state variable models in ecology: methods and applications. Oxford University Press, New York

Clark DL, Leis JM, Hay AC, Trnski T (2005) Swimming ontogeny of larvae of four temperate marine fishes. Mar Ecol Prog Ser 292:287-300

Cowen RK, Paris CB, Srinivasan A (2006) Scaling of connectivity in marine populations. Science 311:522-527

Dawkins R (1976) The selfish gene. Oxford University Press, Oxford

Fiksen Ø, Eliassen S, Titelman J (2005) Multiple predators in the pelagic: modelling behavioural cascades. J Anim Ecol 74:423-429

Fisher R, Leis JM, Clark DL, Wilson SK (2005) Critical swimming speeds of late-stage coral reef fish larvae: variation within species, among species and between locations. Mar Biol 147:1201-1212

Fisher RA (1930) Genetical theory of natural selection. Oxford University Press, Oxford

Fitzpatrick MJ, Ben-Shahar Y, Smid HM, Vet LEM, Robinson GE, Sokolowski MB (2005) Candidate genes for behavioural ecology. Trends Ecol Evol 20:96-104

Folkvord A (2005) Comparison of size-at-age of larval Atlantic cod (Gadus morhua) from different populations based on size- and temperature-dependent growth models. Can J Fish Aquat Sci 62:1037-1052

Fuiman LA, Batty RS (1997) What a drag it is getting cold: partitioning the physical and physiological effects of temperature on fish swimming. J Exp Biol 200:1745-1755

Garrison LP, Michaels W, Link JS, Fogarty MJ (2000) Predation risk on larval gadids by pelagic fish in the Georges Bank ecosystem. I. Spatial overlap associated with hydrographic features. Can J Fish Aquat Sci 57:2455-2469

Giske J, Huse G, Fiksen Ø (1998) Modelling spatial dynamics of fish. Rev Fish Biol Fish 8:57-91

Giske J, Mangel M, Jakobsen P, Huse G, Wilcox C, Strand E (2003) Explicit trade-off rules in proximate adaptive agents. Evol Ecol Res 5:835-865

Grimm V, Railsback S (2005) Individual based modeling and ecology. Princeton University Press, Princeton, NJ

Grimm V, Revilla E, Berger U, Jeltsch F and 6 others (2005) Pattern-oriented modeling of agent-based complex systems: lessons from ecology. Science 310:987-991

Harden Jones FR (1968) Fish migration. Edward Arnold, London

Harden Jones FR, Arnold GP, Greer Walker M, Scholes P (1979) Selective tidal stream transport and the migration of plaice (Pleuronectes platessa L) in the southern North Sea. J Cons Int Explor Mer 38:331-337

Hare JA, Thorrold S, Walsh H, Reiss C, Valle-Levinson A, Jones C (2005) Biophysical mechanisms of larval fish ingress into Chesapeake Bay. Mar Ecol Prog Ser 303: 295-310

Hinckley S, Hermann AJ, Megrey BA (1996) Development of a spatially explicit, individual-based model of marine fish early life history. Mar Ecol Prog Ser 139:47-68

Hinrichsen HH, Schmidt JO, Petereit C, Mollmann C (2005) Survival probability of Baltic larval cod in relation to spatial overlap patterns with their prey obtained from drift model studies. ICES J Mar Sci 62:878-885

Holland JN (1992) Adaptation in natural and artificial systems. MIT Press, Cambridge, MA

Houde E (1997) Patterns and consequences of selective processes in teleost early life histories. In: Chambers RC, Trippel EA (eds) Early life history and recruitment in fish populations. Chapman \& Hall, London, p 173-196

Houston A, McNamara J (1999) Models of adaptive behaviour. Cambridge University Press, Cambridge

Huret M, Runge JA, Chen C, Cowles G, Xu Q, Pringle JM (2007) Dispersal modeling of fish early life stages: sensitivity with application to Atlantic cod in the western Gulf of Maine. Mar Ecol Prog Ser 347:261-274

Huse G (2001) Modelling habitat choice in fish using adapted random walk. Sarsia 86:477-483

Huse G, Strand E, Giske J (1999) Implementing behaviour in individual-based models using neural networks and genetic algorithms. Evol Ecol 13:469-483

Huse G, Johansen GO, Bogstad L, Gjøsæter H (2004) Studying spatial and trophic interactions between capelin and cod using individual-based modelling. ICES J Mar Sci 61: $1201-1213$

Hutchinson JMC, Gigerenzer G (2005) Simple heuristics and rules of thumb: where psychologists and behavioural biologists might meet. Behav Process 69:97-124

Jørgensen C, Ernande B, Fiksen Ø, Dieckmann U (2006) The logic of skipped spawning in cod. Can J Fish Aquat Sci 63:200-211

Larsson AI, Jonsson PR (2006) Barnacle larvae actively select flow environments supporting post-settlement growth and survival. Ecology 87:1960-1966

Leis JM (2007) Behaviour as input for modelling dispersal of fish larvae: behaviour, biogeography, hydrodynamics, ontogeny, physiology and phylogeny meet hydrography. Mar Ecol Prog Ser 347:185-193

Leis JM, Hay AC, Trnski T (2006) In situ ontogeny of behaviour in pelagic larvae of three temperate, marine, demersal fishes. Mar Biol 148:655-669

Lima SL, Dill LM (1990) Behavioral decisions made under the risk of predation - a review and prospectus. Can J Zool 68:619-640

Loose CJ, Dawidowicz P (1994) Trade-offs in diel vertical migration by zooplankton - the costs of predator avoidance. Ecology 75:2255-2263

Lough RG, Potter DC (1993) Vertical distribution patterns and diel migrations of larval and juvenile haddock Melanogrammus aeglefinus and Atlantic cod Gadus morhua on Georges Bank. Fish Bull (Wash DC) 91:281-303

Lough RG, Buckley LJ, Werner FE, Quinlan JA, Edwards KP (2005) A general biophysical model of larval cod (Gadus morhua) growth applied to populations on Georges Bank. Fish Oceanogr 14:241-262

Maley CC, Caswell H (1993) Implementing i-state configuration models for population dynamics - an object-oriented programming approach. Ecol Model 68:75-89 
McNamara JM, Houston AI (1987) Starvation and predation as factors limiting population size. Ecology 68:1515-1519

Menczer F, Belew RK (1996) From complex environments to complex behaviors. Adapt Behav 4:317-363

Mullon C, Cury P, Penven P (2002) Evolutionary individualbased model for the recruitment of anchovy (Engraulis capensis) in the southern Benguela. Can J Fish Aquat Sci 59:910-922

Nielsen R, Munk P (2004) Growth pattern and growth dependent mortality of larval and pelagic juvenile North Sea cod Gadus morhua. Mar Ecol Prog Ser 278:261-270

Olla BL, Davis MW, Ryer CH, Sogard SM (1996) Behavioural determinants of distribution and survival in early stages of walleye pollock, Theragra chalcogramma: a synthesis of experimental studies. Fish Oceanogr 5:167-178

Paris CB, Cowen RK (2004) Direct evidence of a biophysical retention mechanism for coral reef fish larvae. Limnol Oceanogr 49:1964-1979

Peck MA, Buckley LJ, Bengtson DA (2006) Effects of temperature and body size on the swimming speed of larval and juvenile Atlantic cod (Gadus morhua): implications for individual-based modelling. Environ Biol Fish 75:419-429

Persson L, De Roos AM (2003) Adaptive habitat use in sizestructured populations: linking individual behavior to population processes. Ecology 84:1129-1139

Plomin R, DeFries JC, McClearn GE, McGuffin P (2000) Behavioural genetics. Worth Publishers, New York

Railsback SF, Lamberson RH, Harvey BC, Duffy WE (1999) Movement rules for individual-based models of stream fish. Ecol Model 123:73-89

Scheffer M, Baveco JM, Deangelis DL, Rose KA, Vannes EH (1995) Super-individuals a simple solution for modeling large populations on an individual basis. Ecol Model 80:161-170

Editorial responsibility: Alejandro Gallego (Contributing

Editor), Aberdeen, UK
Schwalme K, Chouinard GA (1999) Seasonal dynamics in feeding, organ weights, and reproductive maturation of Atlantic cod (Gadus morhua) in the southern Gulf of St Lawrence. ICES J Mar Sci 56:303-319

Sinclair M (1988) Marine populations. University of Washington Press, Seattle, WA

Skiftesvik AB (1992) Changes in behavior at onset of exogenous feeding in marine fish larvae. Can J Fish Aquat Sci 49:1570-1572

Slotte A, Fiksen Ø (2000) State-dependent spawning migration in Norwegian spring-spawning herring. J Fish Biol 56:138-162

Strand E, Huse G, Giske J (2002) Artificial evolution of life history and behavior. Am Nat 159:624-644

Takasuka A, Aoki I, Mitani I (2003) Evidence of growthselective predation on larval Japanese anchovy Engraulis japonicus in Sagami Bay. Mar Ecol Prog Ser 252:223-238

Varpe $\varnothing$, Fiksen $\varnothing$, Slotte A (2005) Meta-ecosystems and biological energy transport from ocean to coast: the ecological importance of herring migration. Oecologia 146: $443-451$

Vikebø F, Sundby S, Adlandsvik B, Fiksen Ø (2005) The combined effect of transport and temperature on distribution and growth of larvae and pelagic juveniles of ArctoNorwegian cod. ICES J Mar Sci 62:1375-1386

Vikebø F, Jørgensen C, Kristiansen T, Fiksen Ø (2007) Drift, growth, and survival of larval Northeast Arctic cod with simple rules of behaviour. Mar Ecol Prog Ser 347: 207-219

Wright KJ, Higgs DM, Belanger AJ, Leis JM (2005) Auditory and olfactory abilities of pre-settlement larvae and postsettlement juveniles of a coral reef damselfish (Pisces: Pomacentridae). Mar Biol 147:1425-1434

Submitted: June 29, 2006; Accepted: April 30, 2007

Proofs received from author(s): August 24, 2007 